\title{
SIKAP DAN PENGETAHUAN TERHADAP JAMU DI KOMUNITAS YOGA FIRST KLATEN
}

\author{
Ahda Maulida ${ }^{1}$, Indri Kusuma Dewi ${ }^{2}$, Susilo Yulianto ${ }^{3}$ \\ Poltekkes Kemenkes Surakarta Jurusan Jamu
}

\begin{abstract}
Background: Jamu can improve health for the body empirically. The use of jamu has a tendency to back to nature. Jamu is a traditional medicine of Indonesia. Based on preliminary study about attitude and knowledge towards jamu in Yoga First Klaten by interviewing members, there were 5 of 7 members showed positive attitude towards jamu and 3 of 7 members knew about boiled traditional jamu. Methods: The goal of this research is to know attitude and knowledge towards jamu in Yoga First Klaten Community. The kind of the research is quantitative descriptive. Samples were taken by using purposive sampling, there were 50 samples and data was gotten from respondens that fill in the attitude and knowledge towards jamu statement form. Result: The result of attitude has shown that 100\% repondens were kind towards jamu. The result of knowledge has shown that $90 \%$ respondens in a good category and $10 \%$ in a enough category towards jamu. Conclusion: The conclusion is 100\% respondens were kind and $90 \%$ respondens in a good category towards jamu.
\end{abstract}

Keywords: Attitude, Knowledge, Jamu, Member of Yoga First Klaten Community

\section{PENDAHULUAN}

Setiap manusia pada hakekatnya mendambakan hidup sehat dan sejahtera lahir batin. Kesehatan merupakan salah satu kebutuhan dasar manusia, disamping kebutuhan akan sandang, pangan, papan dan pendidikan. Jamu secara empiris dapat meningkatkan kesehatan bagi tubuh. Penggunaan jamu di masyarakat memiliki kecenderungan untuk kembali ke alam (back to nature) dengan memanfaatkan berbagai tanaman obat, karena obat sintetis dirasakan terlalu mahal serta efek samping yang cukup besar sehingga konsumsi jamu di Indonesia cenderung semakin meningkat (Vialin, 2012).

Sejak dulu bangsa Indonesia telah mengenal dan memanfaatkan tumbuhan berkhasiat obat untuk mengatasi masalah kesehatan. Pengetahuan tentang tumbuhan obat tersebut bagian tradisi masyarakat yang diwariskan turun-temurun hingga ke generasi sekarang (Emilda, 2017).

Jamu dapat digunakan untuk pengobatan dan memelihara kesehatan. Meskipun rasanya pahit, namun sejak berabad-abad yang lalu jamu selalu mendapat tempat yang penting dalam kehidupan sebagian masyarakat Indonesia. Sejarah jamu memang tidak diketahui secara pasti, ada pendapat bahwa hal ini dapat ditelusuri pada relief candi sementara istilah jamu (jampi oesada) mungkin juga dapat ditelusuri pada peninggalan tulisan jaman dulu, ada yang mengatakan mungkin ada di naskah Ghatotkacasraya (Mpu Panuluh), Serat Centhini, dan Serat Kawruh Bab JampiJampi Jawi (Aditama, 2014).

Kementerian Pemuda dan Olahraga juga mengajak semua masyarakat Indonesia dari berbagai kalangan untuk 
terus semangat olahraga. Selain berolahraga juga minum jamu tradisional sebagai minuman kesehatan khas Indonesia. Kegiatan ini merupakan bagian dari mengkampanyekan tradisi minum jamu tradisional, hidup sehat, dan membudayakan olahraga (Kemenpora, 2015).

Berdasarkan studi pendahuluan mengenai sikap terhadap jamu yang dilakukan oleh peneliti terhadap anggota komunitas Yoga First Klaten melalui wawancara dengan 7 anggota, terdapat 5 anggota menunjukkan sikap positif terhadap jamu tradisional. Sementara studi pendahuluan mengenai pengetahuan terhadap jamu terdapat 3 dari 7 anggota yang mengetahui tentang jamu tradisional godogan.

Pemanfaatan jamu banyak diterapkan oleh masyarakat Indonesia namun pembahasan karya tulis ini dihususkan pada sikap dan pengetahuan terhadap jamu pada masyarakat yang rajin melakukan olahraga yoga.

\section{METODE PENELITIAN}

Jenis penelitian ini adalah deskriptif kuantitatif yaitu dilakukan terhadap sekumpulan objek yang biasanya bertujuan untuk melihat gambaran fenomena (termasuk kesehatan) yang terjadi di dalam suatu populasi tertentu (Notoatmodjo, 2012). Rancangan penelitian cross sectional yang artinya tiap subjek penelitian hanya diobservasi sekali saja dan pengukuran dilakukan terhadap status karakter atau variabel subjek pada saat pemeriksaan (Notoatmodjo, 2012).

Alat yang digunakan dalam penelitian ini adalah angket. Angket untuk mengungkap karakteristik responden meliputi identitas dan sejumlah pertanyaan tertulis yang berkaitan dengan sikap dan pengetahuan terhadap jamu. Identitas responden meliputi nama, jenis kelamin, umur, pendidikan, dan sumber informasi tentang jamu.

Jalannya penelitian dilakukan dengan:

1. Tahap Persiapan

Tahap persiapan meliputi pengajuan judul, pelaksanaan studi pendahuluan pada beberapa anggota Komunitas Yoga First Klaten, penyiapan alat pengumpulan data (angket), pelaksanaan uji validitas dan reliabilitas, pengajuan proposal, dan seminar proposal.

2. Prosedur Pengumpulan Data

a. Prosedur perijinan pertama mendapatkan ijin dari pemilik Yoga First Klaten untuk melaksanakan penelitian.memilih responden dan menjelaskan terlebih dahulu tentang tujuan dan manfaat penelitian pada responden.

b. Apabila responden telah mengetahui tujuan dan manfaat penelitian, responden diminta untuk menandatangani surat pernyataan bersedia menjadi responden (informed consent), mengisi identitas responden, dan mengisi jawaban dari pernyataan sikap dan pengetahuan terhadap jamu.

3. Tahap Akhir

Tahap akhir meliputi penyusunan laporan karya tulis ilmiah berdasarkan data yang telah terkumpul dilanjutkan seminar hasil penelitian dan revisi.

\section{Analisis Hasil}

Teknik Analisa yang digunakan:

1. Sikap

Menurut Juliani (2014) kriteria objektif sikap sebagai berikut: 
a. Bersikap positif jika responden menjawab dengan skor $68-108$ atau $63 \%-100 \%$

b. Bersikap negatif jika responden menjawab dengan skor $27-67$ atau $25 \%-62 \%$

2. Pengetahuan

Skor hasil jawaban responden dihitung dengan rumus:

$$
\mathrm{N}=\frac{f}{\mathrm{n}} \times 100 \%
$$

Keterangan:

$\mathrm{N}=$ nilai skor pengetahuan

$f=$ jumlah pernyataan yang dijawab benar

$\mathrm{n}=$ total seluruh pernyataan

Menurut Arikunto dalam Wawan (2011) kriteria pengetahuan:
a. Baik
: Hasil presentase 76\% - $100 \%$
b. Cukup : Hasil presentase 56\% - $75 \%$
c. Kurang : Hasil presentase $<56 \%$

HASIL DAN PEMBAHASAN

Tabel 1. Distribusi Frekuensi Responden Menurut Jenis Kelamin,Umur,Pendidikan, dan Informasi Responden di Komunitas Yoga First Klaten

\begin{tabular}{lcc}
\hline Kategori & $\begin{array}{c}\text { Frekuensi } \\
(\mathbf{n = 5 0})\end{array}$ & $\begin{array}{c}\text { Presentase } \\
(\mathbf{\%})\end{array}$ \\
\hline Jenis Kelamin & & \\
\hline Laki-laki & 9 & 18 \\
Perempuan & 41 & 82 \\
\hline Umur & & \\
\hline$<20$ tahun & 2 & 4 \\
$20-40$ tahun & 32 & 64 \\
$>40$ tahun & 16 & 32 \\
\hline Pendidikan & & \\
\hline SMP & 2 & 4 \\
SMA & 7 & 14 \\
D3 & 8 & 16 \\
S1 & 21 & 42 \\
S2 & 5 & 10 \\
Tidak diketahui & 7 & 14 \\
\hline
\end{tabular}

\begin{tabular}{lrr}
\hline Sumber Informasi & & \\
\hline Teman & 16 & 32 \\
Orang tua & 30 & 60 \\
Televisi & 1 & 2 \\
Internet & 3 & 6 \\
\hline Sumber: Data Primer
\end{tabular}

Sumber: Data Primer, 2018

Tabel 2. Distribusi Frekuensi Sikap Terhadap Jamu

\begin{tabular}{lcc}
\hline Kategori & Frekuensi & $\begin{array}{c}\text { Presentase } \\
(\boldsymbol{\%})\end{array}$ \\
\hline Mendukung & 50 & 100 \\
\hline $\begin{array}{l}\text { Tidak } \\
\text { Mendukung }\end{array}$ & 0 & 0 \\
\hline \multicolumn{1}{c}{ Jumlah } & $\mathbf{5 0}$ & $\mathbf{1 0 0}$ \\
\hline
\end{tabular}

Sumber: Data Primer, 2018

Berdasarkan tabel 2 di atas, 50 responden menyatakan bersikap positif terhadap jamu.

Tabel 3.Distribusi Frekuensi Pengetahuan Terhadap Jamu

\begin{tabular}{lcc}
\hline Kategori & Frekuensi & $\begin{array}{c}\text { Presentase } \\
(\boldsymbol{\%})\end{array}$ \\
\hline Baik & 45 & 90 \\
Cukup & 5 & 10 \\
Kurang & 0 & 0 \\
\hline \multicolumn{1}{c}{ Jumlah } & $\mathbf{5 0}$ & $\mathbf{1 0 0}$ \\
\hline
\end{tabular}

Sumber: Data Primer, 2018

Berdasarkan tabel 3 di atas, dari 50 responden tentang pengetahuan terhadap jamu, 45 responden (90\%) memiliki pengetahuan yang baik terhadap jamu.

\section{PEMBAHASAN}

Terdapat beberapa faktor yang mempengaruhi sikap seseorang, yaitu pengaruh orang lain yang dianggap penting, media massa, lembaga pendidikan dan lembaga agama. Sikap merupakan suatu respon evaluatif yang hanya akan timbul apabila individu dihadapkan pada suatu stimulus yang menghendaki adanya reaksi individual, respon evaluatif dinyatakan dalam bentuk 
nilai baik-buruk, positif-negatif, menyenangkan-tidak menyenangkan, yang kemudian mengkristal sebagai potensi reaksi terhadap objek sikap (Azwar, 2013).

Berdasarkan penelitian yang telah dilakukan, hasil penelitian sikap terhadap jamu sesuai dengan teori faktor yang mempengaruhi sikap yaitu lembaga pendidikan, $42 \%$ anggota Komunitas Yoga First Klaten berpendidikan sarjana. Pengaruh dari orang lain yang dianggap penting juga merupakan faktor yang mempengaruhi sikap, anggota Komunitas Yoga First Klaten mendapatkan informasi mengenai jamu dari orang tua dan teman. Selain itu media massa juga merupakan faktor yang mempengaruhi sikap, beberapa anggota Komunitas Yoga First mendapatkan informasi mengenai jamu dari televisi dan internet.

Jenis kelamin juga merupakan faktor yang mempengaruhi sikap sesorang. Menurut Dagun dalam Oktavianto (2014) karakteristik laki-laki dan perempuan dari segi psikisnya, bahwa kepribadian seorang perempuan merupakan suatu kesatuan yang terintegrasikan antara aspek-aspek emosionalitas (seperti memiliki tendensi tingkah laku yang sangat pasif, kurang terbuka, dan tidak senang berkompetisi), lebih subjektif dan tergantung suasana hati. Sedangkan pada laki-laki menunjukkan adanya pembagian dan pembatasan yang jelas antara pikiran, rasio, dan emosionalitas (seperti lebih tegas, suka dengan kompetisi, dan jalan pikiran tidak dikuasai oleh emosi, perasaan maupun suasana hati), lebih objektif, dan mengarahkan ke dunia luar. Pada penelitian ini responden baik lakilaki maupun perempuan memiliki sikap mendukung terhadap jamu.
Peneliti mendapatkan hasil bahwa sikap anggota Komunitas Yoga First Klaten terhadap jamu adalah mendukung yang terlihat pada tabel 4.5 , dari $100 \%$ responden semua menyatakan bersikap mendukung terhadap jamu. Hasil penelitian ini sesuai dengan penelitian Triwijayanti (2006) dengan judul Studi Sikap dan Niatan Konsumsi Jamu Pahitan di Surabaya, hasil penelitian tersebut menunjukkan lebih dari $60 \%$ responden memberi penilaian setuju sampai sangat setuju terhadap berbagai bentuk jamu baik berbentuk cair, serbuk, dan padat.

Terdapat beberapa faktor yang mempengaruhi pengetahuan, yaitu pendidikan dan umur (Wawan, 2011). Pengetahuan adalah hasil dari tahu dan ini terjadi setelah orang melakukan penginderaan terhadap suatu objek tertentu. Penginderaan terjadi melalui pancaindera manusia, yakni indera penglihatan, pendengaran, penciuman, rasa, dan raba. Sebagian pengetahuan manusia diperoleh melalui mata dan telinga (Notoatmodjo, 2012).

Berdasarkan hasil penelitian yang telah dilakukan, hasil pengetahuan terhadap jamu sesuai dengan teori faktor yang mempengaruhi pengetahuan yaitu pendidikan dan umur. $42 \%$ anggota Komunitas Yoga First Klaten berpendidikan sarjana, semakin tinggi pendidikan seseorang maka akan mempengaruhi seseorang lebih mudah untuk menerima informasi (Wawan, 2010). 64\% anggota Komunitas Yoga First Klaten berumur 20 - 40 tahun yang tergolong dewasa muda. Masa dewasa muda umumnya berada pada kondisi fisik dan intelektual yang baik (Ninawati, 2005).

Peneliti mendapatkan hasil bahwa pengetahuan anggota Komunitas Yoga 
First Klaten terhadap jamu pada kategori baik sebanyak 45 orang $(90 \%)$ dan kategori cukup sebanyak 5 orang (45\%). Hasil penelitian ini tidak sesuai dengan penelitian Dewi (2016) dengan judul Pengetahuan Ibu tentang Pemanfaatan Tanaman Obat untuk Asam Urat, hasil penelitian tersebut menunjukkan bahwa sebanyak 26 orang atau sebesar (52\%) memiliki pengetahuan yang cukup.

\section{KESIMPULAN DAN SARAN}

Berdasarkan hasil penelitian yang dilakukan di Yoga First Klaten tentang Sikap dan Pengetahuan terhadap Jamu di Komunitas Yoga First Klaten, dapat disimpulkan bahwa:

1. Sikap anggota Komunitas Yoga First Klaten terhadap jamu menunjukkan bahwa $100 \%$ responden bersikap mendukung terhadap jamu.

2. Pengetahuan anggota Komunitas Yoga First Klaten terhadap jamu menunjukkan bahwa 90\% responden mempunyai pengetahuan yang baik terhadap jamu.

\section{DAFTAR RUJUKAN}

Aditama, T. Y. 2014. Jamu \& Kesehatan. Jakarta : Badan Penelitian dan Pengembangan Kesehatan.

Azwar, S. 2013. Sikap Manusia Teori dan Pengukurannya. Yogyakarta : Pustaka Pelajar.

Emilda, dkk. 2017. Pengetahuan Masyarakat tentang Pemanfaatan Tanaman Obat Keluarga (Studi Kasus Kelurahan Situgede, Kecamatan Bogor Barat). Jurnal Sainmatika (Vol. 14 (1) : 12).

Juliani, K. P., dkk. 2014. Hubungan Pengetahuan dengan Sikap Remaja tentang Perilaku Seksual Pranikah pada Siswi Kelas X di SMA Negeri 1
Manado. Manado : Universitas Sam Ratulangi.

Kemenpora. 2015. Asyiknya habis Berolahraga Minum Jamu Tradisional.http://kemenpora.go.id/i ndex/preview/berita/9469. Diakses pada tanggal 22 Oktober 2017.

Ninawati, F. I. 2005. Gambaran Kesejahteraan Psikologis pada Masa Dewasa Muda ditinjau dari Pola Attachment. Jurnal Psikologi (Vol. 3(1) : 50).

Notoatmodjo, S. 2012. Metodologi Penelitian Kesehatan. Jakarta : Rineka Cipta.

Oktavianto, R. 2014. Organization Citizenship Behavior (OCB) ditinjau dari Jenis Kelamin pada Pegawai Dinas Pendidikan Kota Cilegon. [Naskah Publikasi]. Surakarta : Universitas Muhammadiyah Surakarta.

Vialin, G. 2012. Pengalaman Keluarga Mengkonsumsi Jamu dalam Perspektif Sehat Sakit di Desa Jaten Kecamatan Juwiring. [Skripsi]. Surakarta : Universitas Muhammadiyah Surakarta.

Wawan, A. dan A. D. 2011. Teori \& Pengukuran Pengetahuan, Sikap dan Perilaku Manusia. Yogyakarta : Nuha Medika. 